\title{
Cuticular signature in the development of Polistes versicolor
}

J.H. dos S. Brito ${ }^{1}$, T.S. Montagna ${ }^{1}$, F.S. Maia ${ }^{2}$, W.F. Antonialli-Junior ${ }^{1,3}$ and

C.A.L. Cardoso ${ }^{1,2}$

${ }^{1}$ Programa de Pós-Graduação em Recursos Naturais, Universidade Estadual de Mato Grosso do Sul, Dourados, MS, Brasil

${ }^{2}$ Centro de Pesquisa em Biodiversidade,

Universidade Estadual de Mato Grosso do Sul, Dourados, MS, Brasil

${ }^{3}$ Programa de Pós-Graduação em Entomologia e Conservação da Biodiversidade,

Universidade Federal da Grande Dourados, Dourados, MS, Brasil

Corresponding author: C. A. L. Cardoso

E-mail: claudia@uems.br

Genet. Mol. Res. 14 (4): 12520-12528 (2015)

Received April 23, 2015

Accepted August 11, 2015

Published October 16, 2015

DOI http://dx.doi.org/10.4238/2015.October.16.19

ABSTRACT. Wasps belong to societies that are highly complex and diverse, especially considering social organization and parental care. They use chemicals in their daily communication, and act incisively in recognition of mates and non-nest mates, and can even identify individuals of different castes. In this study, cuticle composition was examined during the development of Polistes versicolor from the egg stage to adulthood, with the aim to assess changes in the chemical signature of the species, using gas chromatography. Linear alkanes and branched alkanes were identified that were important to distinguish the various developmental stages of $P$. versicolor. The variation in the linear alkanes and branched alkanes was quantitative, since most of them are present in all stages, with the exception of some linear alkanes that uniquely characterized the egg stage. At the egg stage, differences were predominant for linear alkanes $\mathrm{C}_{8}, \mathrm{C}_{24}, \mathrm{C}_{27}$, and $\mathrm{C}_{29}$. For the larval instars, there was a predominance of linear alkanes $\mathrm{C}_{8}, \mathrm{C}_{22}$ and $\mathrm{C}_{24}$ to $\mathrm{C}_{30}$. In the pre-pupae, pupae and adult stages, $\mathrm{C}_{8}, \mathrm{C}_{22}, \mathrm{C}_{24}$, and $\mathrm{C}_{26}$ to $\mathrm{C}_{30}$ showed a higher abundance during later developmental stages. The addition to branched alkanes increased their 
abundance from the egg (13.52\%) to adult $(22.96 \%)$ stages.

Key words: Social insects; Wasp; Polistes versicolor; Larval instars; Surface pheromones; Hydrocarbons

\section{INTRODUCTION}

The wasp Polistes versicolor is an eotropical species that can be found from Costa Rica to Argentina. It is characterized mainly by its eusociality, with nests having a single comb. Colonies may be started by a single fertilized female, or by two or more fertilized females and layers (Nagamati et al., 2010). The development of $P$. versicolor is holometabolous, with five larval instars (Prezoto and Gobbi, 2005; Pinheiro et al., 2011). Like other social wasps, P. versicolor exhibits distribution of labor, cooperation care of the young, and overlapping generations; these features contribute to maintaining colony cohesion (Gullan and Cranston, 2010).

The main factor influencing colony cohesion of social insects is communication, which can be carried out through visual, audible, tactile and chemical signals, with the latter, called semiochemicals, being the most effective. Semiochemicals are used for various functions such as defense, foraging, and task attributions, among others (Lorenzi et al., 2004; Zarbin and Rodrigues, 2009; Ferreira-Caliman et al., 2013). These compounds, when used in intra-specific communication (Zarbin and Rodrigues, 2009), and found in insect cuticle (Ferreira-Caliman et al., 2013).

Semiochemicals also work in signaling processes both within and between colonies (Blomquist and Bagneres, 2010), and in the ability of individuals to recognize and distinguish roommate and non-nest mates (Gamboa, 2004; Lucas et al., 2005; Cotoneschi et al., 2007; Ferreira-Caliman et al., 2010; Kroiss et al., 2011; Bos et al., 2012; Costanzi et al., 2013). Indeed, interactions mediated by surface compounds are observed among insects in general, and several studies have been conducted specifically with wasps of the genus Polistes (Dapporto et al., 2004; Dapporto et al., 2005; Cotoneschi et al., 2007; Dapporto et al., 2007; Dapporto et al., 2008; Cotoneschi et al., 2009; Lorenzi et al., 2011).

The cuticular hydrocarbons, mostly linear alkanes, branched alkanes and alkenes are used during communication of the insects. (Howard and Baker, 2004; Dapporto et al., 2005; Devigne and Biseau, 2012; Gołębiowski et al., 2013; Olaniran et al., 2013). According to Krasnec and Breed (2013), the cuticular hydrocarbons can be specific to each colony and lead to qualitative and quantitative variations between colonies. These compounds can also vary throughout the development stages.

It has been previously shown that the cuticular chemical signature differs between the different developmental stages. For example, for the insect Riptortus pedestris, the cuticular composition of eggs, larvae and adults have presented qualitative and quantitative differences (Yoon et al., 2012). In a study on the fly Lucilia sericata, quantitative differences were reported between cuticular compounds at different developmental stages (Golebiowski et al., 2012). Brown et al. (1991) identified quantitative differences inthe composition of cuticular hydrocarbons of larvae, pre-pupae, pupae and adults of the social waspVespula germanica. According to Lorenzi et al. (2004), cuticular hydrocarbons found in Polistes dominulus increased quantitatively following emergence to the adulthood stage. Dapporto et al. (2007) studied the chemical profiles of eggs and cuticle of beta and alpha female $P$. dominulus wasps in experimental colonies, and found that the chemical profile of each egg type corresponded to the profile of the respective female.

Methods and techniques of high precision are required for the analysis of cuticular compounds in insects. High-resolution techniques are fundamental to determine cuticle composition, and may provide an improved understanding of physiological functions, and between-individual 
interactions of wasps (Golebiowski et al., 2013). A method commonly used for this purpose is gas chromatography (Gamboa et al., 1996; Lorenzi et al., 2004; Kroiss et al., 2011; Ferreira et al., 2012; Costanzi et al., 2013).

A few studies have investigated the cuticular composition of eusocialist wasps from egg to adult. With this in mind, the aim of the current study was to evaluate changes in cuticular composition throughout the development of the wasp Polistes versicolor.

\section{MATERIAL AND METHODS}

\section{Collection and material selection}

Ten colonies of $P$. versicolor wasps were collected between February and March 2013 from the forest region of the "Coconut Farm", in Dourados / State of Mato Grosso do Sul, Brazil (S $22^{\circ} 12^{\prime} 43^{\prime \prime}$, W $\left.54^{\circ} 54^{\prime} 53^{\prime \prime}\right)$. Colonies were extracted at night by wrapping a plastic container around the nest then detaching the stalk of the substrate clamping. Next, the entire population was taken to the laboratory and stored at $4^{\circ} \mathrm{C}$ for up to five days. During this period, samples of developmental stages were weighed and cataloged prior to extraction of the cuticle components for chemical analyses.

Cuticular chemical composition was analyzed at all stages of insect development: eggs, larvae, pre-pupae, pupae, and adults. To confirm the five larval instars, widths of the head capsule of 758 larvae from all ten colonies were measured using a stereomicroscope (Zeiss Stemi 2000, Edmund Optics Inc, Barrington, NJ ,USA), equipped with an ocular micrometer and camera digital. Data were compared to results reported by Pinheiro et al. (2011) for this species, and larvae were classified into five instars (I, II, III, IV, and V).

All individuals (eggs, larvae, pre-pupae, pupae and adults) were killed by freezing, then stored at $-20^{\circ} \mathrm{C}$ until further processing for extraction. For all developmental stages, cuticular hydrocarbon extraction was performed on whole individuals.

Gas chromatography with flame ionization detection (GC-FID) and gas chromatography coupled to mass spectrometry (GC-MS) were employed to evaluate the of the cuticle of eggs, all larval instars, pre-pupae, pupae and adults; five samples from each stage were analyzed from each of the ten colonies.

\section{Extraction}

Cuticular constituents were extracted from each individual, using $1 \mathrm{~mL}$ hexane (HPLC grade (Tedia, Fairfield, OH, USA) for 2 min. Following filtration, the solvent was removed using an exhaustion chapel. Each extract was then dissolved in $50 \mu \mathrm{L}$ hexane, for chromatographic analysis. Before the extraction of the hexane was also analyzed by chromatography under the same conditions as the samples to confirm its purity.

\section{Gas chromatography with flame ionization detector (GC-FID)}

Samples and standards $\left(C_{7}-C_{31}\right.$, Sigma Aldrich with purity $\left.\geq 90 \%\right)$ were analyzed by GCFID(Focus GC, Thermo Scientific, San Jose, CA, USA) with an OV-5 capillary column (Ohio Valley Specialty Company, Marietta, OH, USA) having 5\% phenyl dimethylpolysiloxane (30-m length, $0.25-\mathrm{mm}$ diameter, and $0.25-\mathrm{mm}$ film thickness). Each sample $(1 \mu \mathrm{L})$ was injected in splitless mode. The injector and detector were maintained at $280^{\circ} \mathrm{C}$, using $\mathrm{N}_{2}$ as the carrier gas $(99.999 \%$; flow rate $1.0 \mathrm{~mL} / \mathrm{min}$ ). The initial oven temperature was $50^{\circ} \mathrm{C}$, which reached $280^{\circ} \mathrm{C}$ at a rate of $6^{\circ} \mathrm{C}$ 
I min, then remained at $280^{\circ} \mathrm{C}$ for $10 \mathrm{~min}$. Chromatograms were recorded using Chrom Quest 5.0 software (Focus GC, Thermo Scientific, San Jose, CA, USA), and analyzed by means of the Workstation Chrom Data Review software (Focus GC, Thermo Scientific, San Jose, CA, USA).

\section{Gas chromatography with mass spectrometer detector (GC-MS)}

A gas chromatograph (GC- 2010 Shimadzu, Kyoto, Japan) mass spectrometer detector (QP 2010), with a capillary column DB -5 (J \& W, Folsom, California) and 5\% phenyldimethylpolysiloxane (30-m length, 0.25-mm diameter, and 0.25-mm film thickness) was used. Analysis conditions were: carrier gas helium (99.999\%; flow rate $1 \mathrm{~mL} / \mathrm{min}$ ); and injection volume 1 $\mu \mathrm{L}$ in splitless mode. The oven temperature conditions were as described for GC-FID. The injector, detector and transfer line were kept at $280^{\circ} \mathrm{C}$. Parameters included scanning MS voltage electron impact ionization of $70 \mathrm{eV}$; a range of mass $45-600 \mathrm{~m} / \mathrm{z}$ and scan of $0.5 \mathrm{~s}$.

Data processing was performed using a signal to noise ratio of three. The criterion for accepting a detected compound was a minimum of 900 of similarity match, as well as manual inspection of the quality of the mass spectrum for each compound. Identification of compounds was performed using standards $\left(\mathrm{C}_{7}-\mathrm{C}_{31}\right)$, retention index and tentative identification, by comparing the mass spectra of unknown components with those of the Wiley mass spectra library (Wiley MS $6^{\text {th }}$ Edition). Relative area percent for each chromatographic peak was employed as abundance approach to evaluate the contribution of each compound area to the total area, and for comparisons between samples. The sum of all peak areas was considered for $100 \%$ of each sample, and each peak was assigned a percentage corresponding to its area.

\section{Statistical analysis}

Data obtained by chromatography were first analyzed by multivariate analysis of variance (MANOVA) of relative percentage areas, to obtain individual $P$ and $\mathrm{F}$ values. Principal component analysis (PCA) followed by MANOVA was then carried out using the software program SYSTAT 12 (Sigma Plot, San Jose, CA, USA).

\section{RESULTS}

Compounds identified are presented in Table 1. Values of the relative standard deviation employing abundance were less than $1 \%$ within the same developmental stage, indicating that quantities of linear alkanes did not differ in each developmental stage for individuals from the same colony.

When abundance of compounds in each stage of the ten colonies were compared, the relative standard deviation was less than $2.5 \%$, indicating that even among colonies, differences were not significant. In the differentiation analysis employing MANOVA, only the linear alkane $\mathrm{C}_{28}$ was significant in explaining the differences between the colonies $(F=5.453 ; P=0.020)$.

Based on $P$ and $F$ values (Table 1 ), only $C_{25}$ and $C_{28}$ were not significant to distinguish the nine stages of development of $P$. versicolor. In general, differences were qualitative and quantitative for compounds in various stages of development (Figure 1). At the egg stage, differences were predominant for linear alkanes $\mathrm{C}_{8}, \mathrm{C}_{24}, \mathrm{C}_{27}$, and $\mathrm{C}_{29}$. For the larval instars, there was a predominance of linear alkanes $\mathrm{C}_{8}, \mathrm{C}_{22}$ and $\mathrm{C}_{24}$ to $\mathrm{C}_{30}$. In the pre-pupae, pupae and adult stages, $\mathrm{C}_{8}, \mathrm{C}_{22}, \mathrm{C}_{24}$, and $\mathrm{C}_{26}$ to $\mathrm{C}_{30}$ showed a higher abundance during later developmental stages (Table 1). The addition to branched alkanes increased their abundance from the egg $(13.52 \%)$ to adult $(22.96 \%)$ stages. 


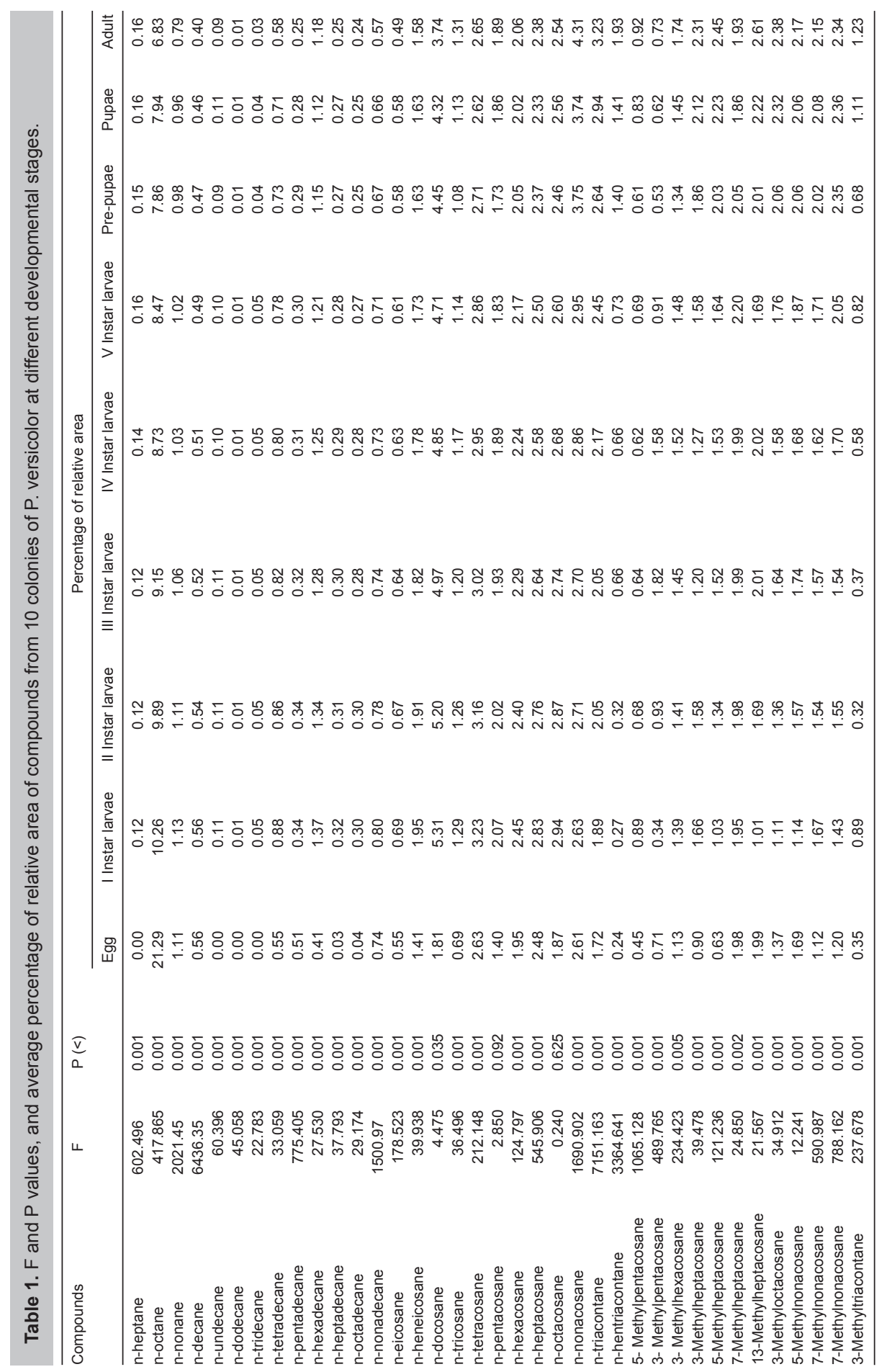



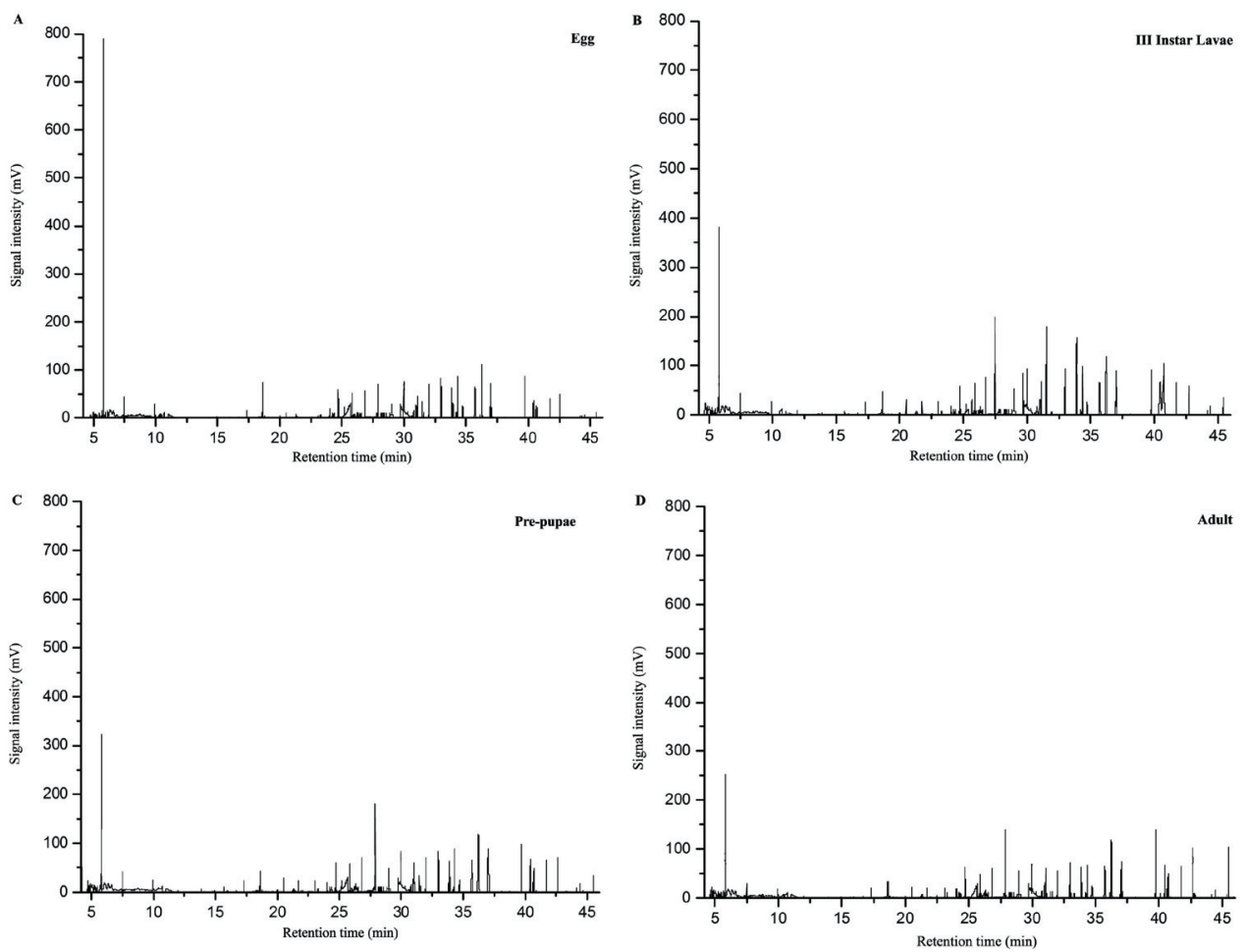

Figure 1. Representative chromatograms of developmental stages of P. versicolor (A) eggs; (B) III instar larvae; (C) pre-pupae and (D) adult stages.

In the current study, linear and branched alkanes were important to define different stages of development (Figure 2 ).

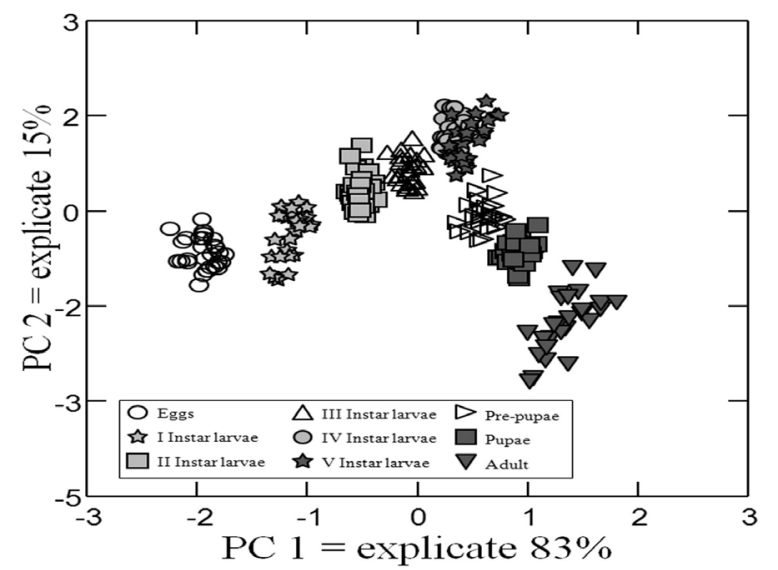

Figure 2. Principal components analysis in all stages of development of P. versicolor. There are nine distinct groupings, based on the different development stages, with Wilk's Lambda of $0.003, F=578.758$, and $P<0.001$, according to the compound composition of samples. The first and second principal components analysis (PCA) explained 83 and $15 \%$ of the results, respectively. 


\section{DISCUSSION}

The ten colonies showed no significant differences statistical. This similarity can be explained by the fact that those colonies were nesting in the same area, presenting some level of kinship among wasps from the different colonies, and thus resulting in a similar cuticular chemistry. Moreover, environmental factors may be relevant (Young and Schal, 1997), and exogenous components from feed and nest substrate, among others, may influence the chemical composition of the cuticle, which could increase these similarities between nests from similar environments (Sorvari et al., 2008; Zweden et al., 2009).

Significant statistical differences were observed in the chemical composition of cuticles of wasps at the various stages of development of the species. Brown et al. (1991) observed qualitative similarities between the composition of cuticular hydrocarbons of Vespula germanica from different colonies, but showed quantitative differences in the proportions of linear alkanes, alkenes and branched alkanes in the cuticular analysis of this species. On the other hand, Dapporto et al. (2004) analyzed branched hydrocarbons and saturated and unsaturated alkanes present in the cuticle of adult colonies of $P$. dominulus, and observed that colonies of the same geographical population presented more similarity in cuticular chemical composition than did colonies from different locations.

In the study, linear and branched alkanes were important to define different stages. Cotoneschi et al. (2009), who analyzed $P$. dominulus larvae wasp and identified, in addition to linear alkanes, branched compounds such as alkanes and alkenes. These compounds were also important to distinguish the chemical signature of larvae, pupae and adult Calliphora vomitoria flies (Gołębiowski et al., 2013), and parasitoid Dibrachys cavus wasps of different ages (Ruther et al., 2011).

It should be noticed that, in the egg stage, the linear alkanes $C_{7}, C_{11}, C_{12}$, and $C_{13}$ were not identified, and smaller amounts of branched alkanes were detected. Yoon et al. (2012), studying the Riptortus pedestris bedbug, found qualitative differences in the cuticular composition of eggs compared to other stages of development and only at the egg stage, the compounds $C_{28}$ and $C_{30}$ were not detected.

Differences between eggs and other stages of development can be at least in part explained by substances present in the Dufour gland (Billen, 2008), which help in differentiating eggs of different castes. According to Bonckaert et al. (2012), in a study of Vespula vulgaris, cuticular composition of the egg was similar to that of the oviposition female, and also to the Dufour gland of this female. Ayasse et al. (1999) evaluated the cuticular chemical composition of queens, workers and eggs from both castes, as well as samples of the Dufour gland, in Bombus terrestris. These authors found differences in the chemical composition of eggsand adult queens and workers, as well as similarities between the cuticular chemical profiles of eggs and the Dufour glands of adults. According to Dapporto et al. (2007), the chemical profile of the egg cuticle is related to the degree of oviposition of the ovarian development of females.

Among the linear alkanes, the most significant to quantitatively distinguish the different larval instars were $\mathrm{C}_{8}, \mathrm{C}_{22}$, and $\mathrm{C}_{24}-\mathrm{C}_{30}$. On the other hand, $\mathrm{C}_{22}, \mathrm{C}_{24}, \mathrm{C}_{26}, \mathrm{C}_{27}$, and $\mathrm{C}_{28}$ were more quantitatively pronounced in larvae than in other stages of development. Brown et al. (1991) determined quantitative differences in some linear alkanes, such as $\mathrm{C}_{27}$ and $\mathrm{C}_{29}$, in larval and adult $V$. germanica. In a similar study of $P$. dominulus, Cotoneschi et al. (2007) described qualitative and quantitative differences in the cuticle compounds of larvae, which presented linear alkanes $\mathrm{C}_{22}-\mathrm{C}_{34}$ and adults, which presented $\mathrm{C}_{23}-\mathrm{C}_{36}$. In the same study of Cotoneschi et al. (2007), it was found that the linear alkanes were more abundant in the larvae, while in adults there was a greater amount of branched alkanes.

Pre-pupae, pupae and adults presented quantitative variations, with reduced linear 
alkanes and significantly increased branched alkanes, demonstrating an evolution in the cuticular signature of $P$. versicolor throughout its development. Dapporto et al. (2008) found that in the cuticle of $P$. dominulus there was a significant quantitative increase of branched alkanes after adult emergence. Neves et al. (2012) observed that adult Mischocyttarus consimilis, a social wasp, acquire their chemical signature five days after emergence, following social interactions with the substrate and the nest itself. Quantitative variations of linear alkanes, as well as of branched and linear alkenes, between pupae and adults of $P$. dominulus and $V$. germanica have been described (Brown et al., 1991; Lorenzi et al., 2004).

Throughout the developmental cycle of $P$. versicolor, significant variations in the chemical composition of the cuticle were observed. The variation in the linear alkanes and branched alkanes was quantitative, since most of them are present in all stages, with the exception of some linear alkanes that uniquely characterized the egg stage. Branched alkanes also varied significantly in quantity, increasing throughout development of the insect. However, there was no significant variation among different colonies, probably because they were from the same population and may have had close kinship relationships, and exposure to the same environmental factors.

\section{Conflicts of interest}

The authors declare no conflicts of interest

\section{ACKNOWLEDGMENTS}

Research supported by Coordenação Aperfeiçoamento de Pessoal de Nível Superior (CAPES), Fundação de Apoio ao Desenvolvimento do Ensino, Ciência e Tecnologia do Estado de Mato Grosso do Sul (FUNDECT), and Conselho Nacional de Desenvolvimento Científico e Tecnológico (CNPq).

\section{REFERENCES}

Ayasse M, Birnbaum J, Tengo J, van Doorn A, et al.(1999). Caste- and colony-specific chemical signals on eggs of the bumble bee, Bombus terrestris L. (Hymenoptera: Apidae). Chemoecology 9: 119-126.

Billen J (2008). A importância de glândulas exócrinas na sociedade de insetos. In: Vilela EF, Santos IA, Schoereder JH, Serrão JE, Campos LAO, Lino-Neto J (eds). Insetos Sociais: Da biologia à aplicação. 1 edição, Editora: UFV, Belo Horizonte, $87-92$.

Blomquist GJ and Bagnères AG (2010). Insect hydrocarbons: Biology, biochemistry, and chemical ecology. Cambridge University Press, Cambridge, UK.

Bonckaert W, Drijfhout FP, d'Ettorre P, Billen J, et al. (2012). Hydrocarbon signatures of egg maternity, caste membership and reproductive status in the common wasp. J. Chem. Ecol. 38:42-51.

Bos N, Dreier S, Jørgensen CG, Nielsen J, et al. (2012). Learning and perceptual similarity among cuticular hydrocarbons in ants. J. Insect Physiol. 58: 138-146.

Brown WV, Spradbery JP and Lacey MJ (1991). Changes in the cuticular hydrocarbon composition during development of the social wasp, Vespula germanica (F.) (Hymenoptera: Vespidae). Comparative Comp. Biochem. Physiol. B 99: 553-562.

Costanzi E, Bagnères AG and Lorenzi MC (2013). Changes in the hydrocarbon proportions of colony odor and their consequences on nestmate recognition in social wasps. PLoS One. 8: 1-11.

Cotoneschi C, Dani FR, Cervo R, Scala C, et al.(2009). Polistes dominulus (Hymenoptera, Vespidae) larvae show different cuticular patterns according to their sex: workers seem not use this chemical information. Chem. Senses.34:195-202.

Cotoneschi C, Dani FR, Cervo R, Sledge MF, et al. (2007). Polistes dominulus (Hymenoptera: Vespidae) larvae possess their own chemical signatures. J. Insect Physiol. 53: 954-963.

Dapporto L, Dani FR and Turillazzi S (2007). Social dominance molds cuticular and egg chemical blends in a paper wasp. Curr. Biol. 17: 504-505R.

Dapporto L, Lambardi D and Turillazzi S (2008). Not only cuticular lipids: First evidence of differences between foundresses 
and their daughters in polar substances in the paper wasp Polistes dominulus. J. Insect Physiol. 54: 89-95.

Dapporto L, Liebert AE, Starks PT and Turillazzi S (2009). The relationships between cuticular hydrocarbon composition, faunal assemblages, inter-island distance, and population genetic variation in Tuscan Archipelago wasps. Biochem. Syst. Ecol. 37: 341-348.

Dapporto L, Sledge FM and Turillazzi S (2005). Dynamics of cuticular chemical profiles of Polistes dominulus workers in orphaned nests (Hymenoptera, Vespidae). J. Insect Physiol. 51: 969-973.

Dapporto L, Theodora P, Spacchini C, Pieraccini G, et al. (2004). Rank and epicuticular hydrocarbons in different populations of the paper wasp Polistes dominulus (Christ) (Hymenoptera,Vespidae). Insectes Soc. 51: 279-286.

Devigne C and Biseau JC (2012). The differential response of workers and queens of the ant Lasius niger to na environment marked by workers: Ants dislike the unknown. Behav. Processes. 91: 275-281.

Ferreira-Caliman MJ, Nascimento FS, Turatti IC, Mateus S, et al. (2010). The cuticular hydrocarbons profiles in the stingless bee Melipona marginata reflect task-related diferences. J. Insect. Physiol. 56: 800-804.

Ferreira-Caliman MJ, Falcón T, Mateus S, Zucchi R, et al. (2013). Chemical identity of recently emerged workers, males, and queens in the stingless bee Melipona marginata. Apidologie. 44: 657-665.

Ferreira AC, Cardoso CAL, Neves EF, Súarez YR, et al. (2012). Distinct linear hydrocarbon profiles and chemical strategy of facultative parasitism among Mischocyttarus wasps. Genet. Mol. Res. 11: 4351-4359.

Gamboa GJ (2004). Kin recognition in eusocial wasps. Ann. Zool. Fenn. 41: 789-808.

Gamboa GJ, Grudzien TA, Espelie KE and Bura EA (1996). Kin recognition pheromones in social wasps: combining chemical and behavioural evidence. Anim. Behav. 51: 625-629.

Gołebiowski M, Cerkowniak M, Bogus MI, Włóka E, et al. (2013). Free fatty acids in the cuticular and internal lipids of Calliphora vomitoria and their antimicrobial activity. J. Insect. Physiol. 59: 416-429.

Gołebiowski M, Paszkiewicz M, Grubba A, Gasiewska D, et al. (2012). Cuticular and internal n-alkane composition of Lucilia sericata larvae, pupae, male and female imagines: application of HPLC-LLSD and GC/MS-SIM. Bull. Entomol. Res. 102: $453-460$.

Gullan PJ and Cranston PS (2010). The insects: an outline of entomology. 4th edition, Wiley-Blackwell, Hoboken, New Jersey.

Howard RW and Baker JE (2004). Stage-specific surface chemicals of Plodia interpunctella: 2-acyl-1,3-cyclohexanediones from larval mandibular glands serve as cuticular lipids. Comp. Biochem. Physiol. B 138: 193-206.

Krasnec MO and Breed MD (2013). Colony-specific cuticular hydrocarbon profile in Formica argentea ants. J. Chem. Ecol. 39: 59-66.

Kroiss J, Svatoš A and Kaltenpoth M (2011). Rapid identification of insect cuticular hydrocarbons using Gas ChromatographyIon-Trap Mass Spectrometry. J. Chem. Ecol. 37: 420-427.

Lorenzi MC, Cervo R and Bagnères AG (2011). Facultative social parasites mark host nests with branched hydrocarbons. Anim. Behav. 82: 1143-1149.

Lorenzi MC, Sledge MF, Laiolo P, Sturlini E, et al. (2004). Cuticular hydrocarbon dynamics in young adult Polistes dominulus (Hymenoptera: Vespidae) and the role of linear hydrocarbons in nestmate recognition systems. J. Insect. Physiol. 50: 935-941.

Lucas C, Pho DB, Jallon JM and Fresneau D (2005). Role of cuticular hydrocarbons in the chemical recognition between ant species in the Pachycondyla villosa species complex. J .Insect Physiol. 51: 1148-1157.

Nagamati K Jr, Simokomaki K, Gruber CV and Del Lama MA (2010). Sociogenetic structure of Polistes (Aphanilopterus) versicolor Olivier, 1791 colonies (Hymenoptera, Vespidae, Polistini). Genet. Mol. Biol. 33: 669-675.

Neves EF, Andrade LHC, Súarez YR, Lima SM, et al. (2012). Age-related changes in the surface pheromones of the wasp Mischocyttarus consimilis (Hymenoptera: Vespidae). Genet. Mol. Res. 11: 1891-1898.

Olaniran OA, Sudhakar AVS, Drijfhout FP, Dublon IAN, et al. (2013). A male-predominant cuticular hydrocarbon, 7-methyltricosane, is used as a contact pheromone in the western flower thrips Frankliniella occidentalis. J. Chem. Ecol. 39: 559-568.

Pinheiro RP, Ribeiro B, Zeringotá V, Souza AR, et al. (2011). Técnica alternativa para determinação do sexo larval na vespa social Polistes versicolor. X Congresso de Ecologia do Brasil, 792, São Lourenço.

Prezoto F and Gobbi N (2005). Morfometria dos estágios imaturos de Polistes simillimus Zikán, 1951 (Hymenoptera, Vespidae). Rev. Bras. Zoo. 7: 47-54.

Ruther J, Döring M and Steiner S (2011). Cuticular hydrocarbons as contact sex pheromone in the parasitoid Dibrachys cavus. Entomol. Exp. Appl. 140: 59-68.

Sorvari J, Theodora P, Turillazzi S, Hakkarainen H, et al. (2008). Food resources, chemical signaling, and nestmate recognition in the ant Formica aquilonia. Behav. Ecol. 19: 441-447.

Yoon C, Yang JO, Youn YN and Kim GH (2012). Changes in cuticular hydrocarbons in different developmental stages of the bean bug, Riptortus pedestris (Hemiptera: Alydidae). J. Asia Pac. Entomol. 15: 579-587.

Young HP and Schal C (1997). Cuticular hydrocarbon synthesis in relation to feeding and developmental stage in nymphs of Blattella germanica (Dictyoptera: Blattellidae). Ann. Entomol. Soc. Am. 90: 655-663.

Zarbin PHG, Rodrigues MACM and Lima ER (2009). Feromônios de insetos: Tecnologia e desafios para uma agricultura competitiva no Brasil. Quím. Nova. 32: 722-731.

Zweden JSV, Dreier S and D'ettorre P (2009). Disentangling environmental and heritable nestmate recognition cues in a carpenter ant. J. Insect. Physiol. 55: 158-163.

Genetics and Molecular Research 14 (4): 12520-12528 (2015)

CFUNPEC-RP www.funpecrp.com.br 